\title{
Influence of atmospheric internal variability on the long-term Siberian water cycle during the past 2 centuries
}

\author{
Kazuhiro Oshima ${ }^{1, a}$, Koto Ogata ${ }^{2,3}$, Hotaek Park ${ }^{1}$, and Yoshihiro Tachibana ${ }^{2}$ \\ ${ }^{1}$ Institute of Arctic Climate and Environment Research, Japan Agency for Marine-Earth Science \\ and Technology, Yokosuka, Japan \\ ${ }^{2}$ Weather and Climate Dynamics Division, Mie University, Tsu, Japan \\ ${ }^{3}$ Aerological Observatory, Japan Meteorological Agency, Tsukuba, Japan \\ a currently at: Institute for Environmental Sciences, Rokkasho, Japan
}

Correspondence: Kazuhiro Oshima (oshima@ies.or.jp)

Received: 30 May 2017 - Discussion started: 6 June 2017

Revised: 2 March 2018 - Accepted: 16 March 2018 - Published: 16 May 2018

\begin{abstract}
River discharges from Siberia are a large source of freshwater into the Arctic Ocean, whereas the cause of the long-term variation in Siberian discharges is still unclear. The observed river discharges of the Lena in the east and the $\mathrm{Ob}$ in the west indicated different relationships in each of the epochs during the past 7 decades. The correlations between the two river discharges were negative during the 1980s to mid-1990s, positive during the mid-1950s to 1960s, and became weak after the mid-1990s. More long-term records of tree-ringreconstructed discharges have also shown differences in the correlations in each of the epochs. It is noteworthy that the correlations obtained from the reconstructions tend to be negative during the past 2 centuries. Such tendency has also been obtained from precipitations in observations, and in simulations with an atmospheric general circulation model (AGCM) and fully coupled atmosphere-ocean GCMs conducted for the Fourth Assessment Report of the IPCC. The AGCM control simulation further demonstrated that an east-west seesaw pattern of summertime large-scale atmospheric circulation frequently emerges over Siberia as an atmospheric internal variability. This results in an opposite anomaly of precipitation over the Lena and $\mathrm{Ob}$ and the negative correlation. Consequently, the summertime atmospheric internal variability in the east-west seesaw pattern over Siberia is a key factor influencing the long-term variation in precipitation and river discharge, i.e., the water cycle in this region.
\end{abstract}

\section{Introduction}

The river discharge $(R)$ from the pan-Arctic terrestrial area supplies freshwater, nutrients, and organic matter to the Arctic Ocean. The three great Siberian rivers, the Lena, Yenisei, and $\mathrm{Ob}$ (Fig. 1) account for about $60 \%$ of the total $R$ into the Arctic Ocean and have an important role in the freshwater budget and climate system in the Arctic (e.g., Aagaard and Carmack, 1989, 1994). Numerous studies have investigated the interannual variation and linear trend in the Siberian $R$ (e.g., Berezovskaya et al., 2004; Ye et al., 2004; McClelland et al., 2004, 2006; Rawlins et al., 2006; MacDonald et al.,
2007; Shiklomanov and Lammers, 2009); however they have mainly analyzed the $R$ dataset from a hydrological perspective. Several other studies have been conducted to determine the linkages among atmospheric circulation, moisture transport, precipitation $(P)$, precipitation minus evapotranspiration $(P-E)$, and the $R$ for Siberian rivers using atmospheric reanalysis combined with the $R$ dataset (Fukutomi et al., 2003; Serreze et al., 2003; Zhang et al., 2012; Oshima et al., 2015). To understand such linkages, it is necessary to improve our knowledge of the atmospheric and terrestrial water cycles in the region. 
Theoretically, $P-E$ over a basin, which is the net input of water from the atmosphere to the land surface, corresponds to $R$ at the river mouth as a long-term average. Indeed, they quantitatively agree well for the individual Siberian rivers (e.g., Zhang et al., 2012; Oshima et al., 2015). The $R$ and $P-E$ are strongly affected by the $P$ and associated atmospheric moisture transport over the individual regions. Processes of the atmospheric moisture transport associated with the $P-E$ show regional difference among the Siberian rivers (Oshima et al., 2015). The $P-E$ over the Lena is mainly supplied by a transient moisture flux associated with cyclone activity and that over the $\mathrm{Ob}$ is mainly supplied by a stationary moisture flux associated with seasonal mean wind. Both processes affect the area over the Yenisei.

Regarding the interannual variations, the moisture transport, $P-E, P$, and $R$ also relate to each other, while those relationships have some seasonal time lag due to the large area of the basin, snow accumulation in winter, negative or near zero $P-E$ in summer, and terrestrial processes (e.g., discharge control via dams, permafrost condition associated with runoff process, distributions of lake, wetland and vegetation associated with evapotranspiration) as discussed in Oshima et al. (2015). More details about this are given in the last part of the next section. Fukutomi et al. (2003) elucidated that the interannual variation in summer $P$ over the Lena was negatively correlated with that over the Ob during the 1980s to mid-1990s. The summer $(P-E)$ values of the two rivers and corresponding autumn $R$ values were also negatively correlated in the same period. Furthermore, Fukutomi et al. (2003) indicated that the negative correlations were affected by an east-west seesaw pattern of largescale atmospheric circulation and associated moisture transport over Siberia. When the cyclonic anomaly of atmospheric circulation emerges over the Lena River, the simultaneous anticyclonic anomaly emerges over the Ob River. The cyclonic anomaly induces a convergence of moisture flux over the Lena basin, then increases $P$ and $R$ of the Lena River. In contrast, the anticyclonic anomaly over the $\mathrm{Ob}$ induces a divergence of moisture flux, then decreases $P$ and $R$ of the $\mathrm{Ob}$ River, and vice versa. Thus, the east-west seesaw pattern produced the negative correlation of $R$ values between the Lena and $\mathrm{Ob}$ and negative correlation of $P$ values between the Lena and Ob during the 1980s to mid-1990s. While the influence of cyclone activity on the interannual variations in $P-E$ and $R$ was discussed in their studies (Fukutomi et al., 2004, 2007, 2012), the cause of the negative correlations has not been fully explained, and it is not certain whether the negative correlation occurs in other periods.

The negative correlation noted above was apparent during the 1980s to mid-1990s. More recently, several drastic changes in the terrestrial water cycle have occurred around Yakutsk in eastern Siberia. Increases in $P$ and soil moisture and deepening of the active layer (Ohta et al., 2008, 2014; Iijima et al., 2010; Iwasaki et al., 2010) have been observed, particularly during 2005-2008, and the wet conditions have induced flooding (Fujiwara, 2011; Sakai et al., 2015) and forest degradation (Iwasaki et al., 2010; Iijima et al., 2014; Ohta et al., 2014). Moreover, effects of permafrost degradation on changing thermokarst lakes and landscapes have been reported in the last 2 decades (Fedorov et al., 2014). While these are local changes, the observed results suggest that some changes on a large spatial scale also occurred in this region in recent decades. Indeed, Iijima et al. (2016) showed that the increase in $P$ and the wet conditions in eastern Siberia during the mid-2000s were affected by cyclone activity accompanied by changes in large-scale atmospheric circulation over Siberia. This suggests that the relationship between the Lena and $\mathrm{Ob}$, which was negatively correlated during the 1980s to mid-1990s, recently changed. However, the long-term variation and its effects on the water cycle in this region are still unclear.

To examine the long-term variation in $R$ of the Lena and Ob rivers, in addition to the observed $R$ during the past 7 decades, we analyzed reconstructed $R$ based on tree rings during the past 2 centuries. We investigated whether the negative correlation of $R$ between the Lena and Ob occurred before the 1980s. We further examined an influencing factor on the long-term variation in $R$ and $P$ and the associated atmospheric circulation using atmospheric reanalyses and simulations with an atmospheric general circulation model (AGCM) and atmosphere-ocean coupled models archived in the World Climate Research Programme's Coupled Model Intercomparison Project phase 3 (CMIP3; Meehl et al., 2007).

\section{Data and analysis methods}

Monthly $R$ observed near the river mouths of the Lena and $\mathrm{Ob}$ (i.e., Kusur and Salehard, Fig. 1) from the Arctic-Rapid Integrated Monitoring System for the period of 1936-2009 (http://rims.unh.edu/; last access: 26 April 2018) and annual $R$ reconstructed based on tree rings for the period of 1800 1990 (MacDonald et al., 2007, https://agupubs.onlinelibrary. wiley.com/doi/abs/10.1029/2006JG000333; last access: 26 April 2018) were used. While the negative correlation was seen during the 1980s to mid-1990s, the timescale of the negative correlation seems to be 1 or 2 decades. To detect a robust tendency of the correlation, we made subsets of the dataset and increased sample size of data. In addition to the entire period, we analyzed subsets of 150 -year periods for the reconstructed $R$. There is a 191-year record of reconstructed $R$, and we produced five subsets of 150-year records, with the start years delayed successively by 1 decade.

Monthly $P$ from the Global Precipitation Climatology Center (GPCC; Schneider et al., 2013) was compared to the $R$. While we used the GPCC product here, it has been confirmed that the $P$ from the other products (e.g., PREC/L: Chen et al., 2002; APHRODITE: Takashima et al., 2009; Yatagai et al., 2012) also have strong positive correlation 


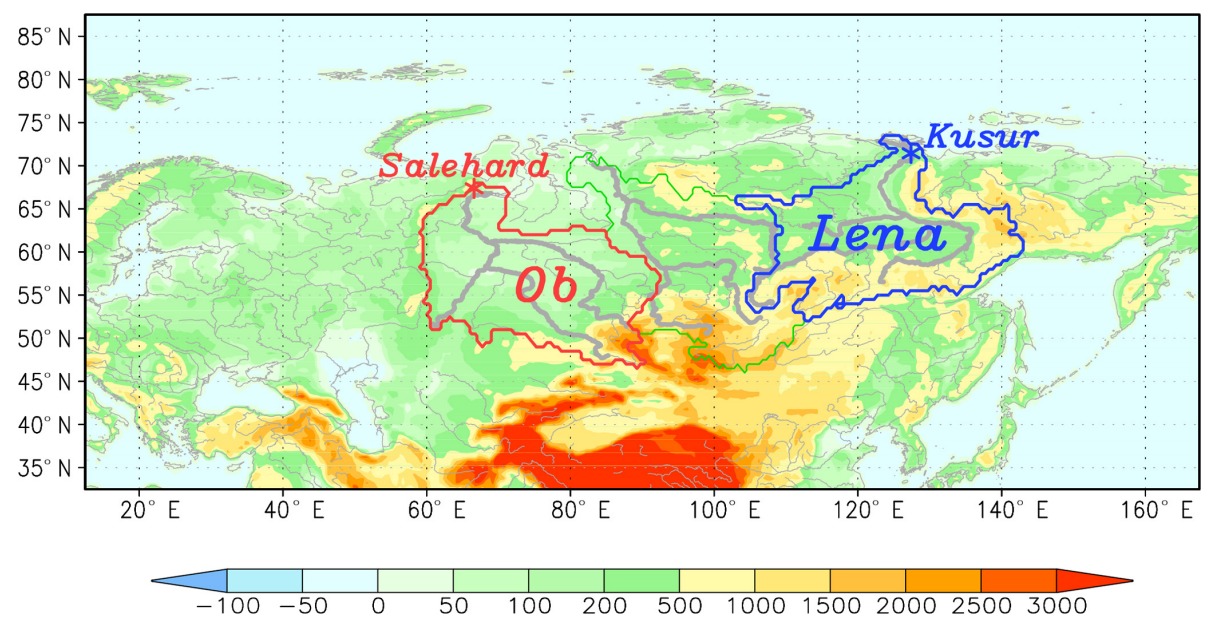

Figure 1. Map of the study area in Siberia. The colored solid contours show the boundaries of each river basin (Lena is in blue and Ob is in red). The asterisks denote the locations of Kusur and Salehard, which are the observation stations nearest the river mouths. The color shades and thick gray lines denote elevation and major flow paths, respectively.

with $R$ for the Lena and $\mathrm{Ob}$ rivers (Oshima et al., 2015). For simplicity, we defined the area of $50-70^{\circ} \mathrm{N}$ and 110 $135^{\circ} \mathrm{E}$ as the Lena region and the area of $50-70^{\circ} \mathrm{N}$ and $60-85^{\circ} \mathrm{E}$ as the $\mathrm{Ob}$ region. The area-averaged $P$ over these regions corresponded well with the averages over the individual river basins. The correlations during 1901-2010 were 0.89 for the Lena and 0.86 for the Ob. In analyses of atmospheric circulation, geopotential height at $500 \mathrm{hPa}(Z 500)$ from two atmospheric reanalyses, the Japanese 55-year Reanalysis (JRA-55; Kobayashi et al., 2015; Harada et al., 2016), and the National Oceanic and Atmospheric Administration - Cooperative Institute for Research in Environmental Sciences (NOAA/CIRES) Twentieth Century Reanalysis (20CR; Compo et al., 2011) was used. The time period of the $P$ and $Z 500$ datasets was from 1901 to 2010, except for JRA-55, which started from 1958.

There are long-term records of tree-ring-reconstructed $R$ values over the past 2 centuries, whereas the meteorological data are limited to the 20th century. To examine the longterm variations and intrinsic atmospheric circulation (i.e., internal variability, teleconnection, and feedback) associated with the $P$, a 300 -year control simulation was performed with an AGCM developed by the Center for Climate System Research, University of Tokyo, and the National Institute for Environmental Studies (Numaguti et al., 1995, 1997). The setting of the control simulation is the same as in Ogata et al. (2013). The horizontal resolution is about $300 \mathrm{~km}$ and the vertical discretization comprises 20 layers (T42L20). It started from a state of rest with constant temperature and was forced by the climatological seasonal cycle of sea surface temperature (SST), sea ice, and fixed greenhouse gases (GHGs) as boundary conditions. We excluded the first 5 years of data from the 300-year simulation as the spin-up time. For the AGCM control simulation, we made 15 subsets of 150-year records, with the start years delayed successively by 1 decade. As in Numaguti (1999) and Kurita et al. (2005) based on the same AGCM with the same horizontal resolution, the spatial pattern and seasonal cycle of simulated $P$ and atmospheric circulation over Siberia are generally consistent with the observed features in the seasonal timescale.

In addition, control simulations under preindustrial conditions (PICTL) and "the 20th century climate in coupled models" (20C3M) simulations in the CMIP3 multi-models conducted for the Fourth Assessment Report of the Intergovernmental Panel on Climate Change (IPCC AR4, Meehl et al., 2007; IPCC, 2007) were compared to the AGCM control simulation. The 20C3M and PICTL simulations were forced by the GHG increasing as observed through the 20th century and the constant preindustrial levels of GHGs, respectively. While the time periods of the CMIP3 simulations were different among the models, the $20 \mathrm{C} 3 \mathrm{M}$ simulations were from 1850-1900 to 2000-2001. The PICTL simulations had time records from 81 to 1001 years. We analyzed the PICTL simulations that were longer than 150 years and made subsets of 150-year records with the start years delayed successively by 5 decades in each of the PICTL simulations. All of the 23 models with the multi-ensemble members in the CMIP3 simulations under the PICTL and 20C3M scenarios were used.

While the reconstructed $R$ comprises an annual value, we analyzed seasonal mean values for the observed $R, P$, and $Z 500$. There are two reasons to analyze seasonal mean values: the first is a seasonal time lag between $P$ and $R$ for both the Lena and $\mathrm{Ob}$ rivers, and the second is a large seasonality in $P$ and $R$. As in Tachibana et al. (2008) for the Amur River and Arpe et al. (2014) for the Volga River, it is expected that the summer $P-E$ may correspond to autumn $R$, and the summer $P-E$ and $P$ are governed by atmospheric circulation in summer. Using a similar method of Tachibana 
Table 1. Correlation coefficients among the summer $P$, annual $P$, autumn $R$, and annual $R$ for the Lena and Ob rivers during 1936-2009. The summer (autumn) averaging period is from June to September (from August to October). The $P$ and $R$ are based on Arctic-RIMS and GPCC. All values are above the $99 \%$ confidence level. Bold values are specifically described in the text.

\begin{tabular}{lrrrr}
\hline Lena & Summer $P$ & Annual $P$ & Autumn $R$ & Annual $R$ \\
\hline Summer $P$ & 1.00 & $\mathbf{0 . 9 1}$ & $\mathbf{0 . 7 9}$ & 0.66 \\
Annual $P$ & & 1.00 & 0.72 & 0.73 \\
Autumn $R$ & & & 1.00 & $\mathbf{0 . 7 9}$ \\
Annual $R$ & & & & 1.00 \\
\hline Ob & Summer $P$ & Annual $P$ & Autumn $R$ & Annual $R$ \\
\hline Summer $P$ & \multirow{2}{*}{1.00} & $\mathbf{0 . 6 4}$ & $\mathbf{0 . 6 3}$ & 0.57 \\
Annual $P$ & & 1.00 & 0.47 & 0.57 \\
Autumn $R$ & & & 1.00 & $\mathbf{0 . 9 1}$ \\
Annual $R$ & & & & 1.00 \\
\hline
\end{tabular}

et al. (2008) ad Oshima et al. (2015), we compared all possible combinations of the seasonal averaging period for $P-E$ and $R$. As a result, a pairing of the summer period from June to September and the autumn period from August to October showed high correlation between summer $P$ and autumn $R$ and is best match for the Lena and Ob rivers. The correlations during 1936-2009 are 0.79 for the Lena and 0.64 for the $\mathrm{Ob \text {, }}$ both significant above the $99 \%$ confidence level (Table 1). In addition, due to the large amount of and large variability in water vapor in summer, it is expected that the interannual variations in summer $P$ and corresponding autumn $R$ dominate the annual values. While those were still indicated in the previous studies (Fukutomi et al., 2003; Zhang et al., 2012), we confirmed the contribution of seasonal values of $P$ and $R$ to annual values. The correlation between the summer $P-E$ (autumn $R$ ) and its annual value is $0.91(0.79)$ for the Lena, and that for the $\mathrm{Ob}$ is $0.64(0.91)$. Therefore, we used the summer $P$ and Z500 averaged from June to September and autumn $R$ averaged from August to October in the analysis.

\section{Results}

\subsection{Long-term variation}

\subsubsection{Observed and reconstructed river discharges}

Figure 2a shows the time series of observed autumn $R$ at the river mouths of the Lena (red solid line) and $\mathrm{Ob}$ (red dashed line) during the past 7 decades (1936-2009), with 15-year running correlations between them (black line). Although the correlations were strong and negative during the 1980s to mid-1990s as in Fukutomi et al. (2003), they were positive during the 1950s to 1960s and became weak after the 1990s. As mentioned above, these autumn $R$ values correspond to the summer $P$ values. The time series of the summer $P$ over the Lena and $\mathrm{Ob}$ regions (Fig. 2b) indicate a negative corre- lation around the 1910s, during the 1940s to mid-1950s and after the 1980s. The correlations of $P$ were near zero in the 1920 s, and were weak and positive during the 1960s. While there were some differences between the observed $R$ and $P$, the $P$ displayed a strong negative correlation in the 1980 s and positive correlation in the 1960s. These results from the observations indicate that the relationship of $R$ to $P$ between the Lena and $\mathrm{Ob}$ was different in each of the epochs.

Figure 2c shows a long-term time series of tree-ringreconstructed annual $R$ of the Lena and $\mathrm{Ob}$ during the past 2 centuries (1800-1990). Similar to the observations, the correlations of reconstructed $R$ were negative during the 1980s to mid-1990s and positive during the 1950 s to 1960 s, while there was some discrepancy between the observed $P$ and reconstructed $R$ in the early 20th century. The discrepancy may be due to error and uncertainty both in the observation and reconstruction. The observation stations of $P$ are sparse in Siberia and measuring $P$ is difficult such as wind-induced undercatch, wetting, and evaporation losses. While the reconstructed $R$ is based on the tree-ring width, the tree-ring width has an indirect relationship with the $R$ and both are mainly related through the $P$. There are also other influences such as air temperature, solar radiation, and nitrogen. In addition, the tree-ring width is affected by meteorological conditions during the growing season in summer and there must be less contribution from the conditions during winter. As a result, the reconstructed $R$ values can explain $43 \%$ of the observed variability for the Lena and $51 \%$ for the $\mathrm{Ob}$ (MacDonald et al., 2007). In the 19th century, the correlations of reconstructed $R$ were strong and negative in some epochs $(1810 \mathrm{~s}, 1850 \mathrm{~s}$, and 1890s) and moderate or weak and positive in some other epochs (1880s and 1900s). These results also indicate that the relationship between the Lena and $\mathrm{Ob}$ differed in each of the epochs. However, it is noteworthy that negative correlations were frequently seen in the time series of reconstructed $R$ (black line in Fig. 2c). As shown by the red bar histogram in Fig. 3a, many of the correlations for reconstructed $R$ were negative. The correlations of observed $R$ and $P$ also tended to have negative values, although these results may not be as robust due to relatively short records (observed $R: 74$ years, $P: 111$ years). It is considered that the long-term change on a decadal timescale or long-term trend may affect the correlations in Fig. 2. While Fukutomi et al. (2003) and MacDonald et al. (2007) discussed the longterm variations on a decadal timescale, it seems that the longterm changes do not affect the time series of the correlations. Indeed, when we remove the 19-year running mean from the raw time series of $P$ and $R$ in Fig. $2 \mathrm{a}-\mathrm{c}$, the correlations do not change so much (not shown) and there is the tendency of frequent negative correlation. To quantitatively show a tendency of the correlation, we calculated median and skewness as a metric of the frequent distribution of the correlations. The skewness is a measure of asymmetry of frequency distributions. When the frequent distribution is distributed in the negative (positive) side, the skewness has a positive (nega- 

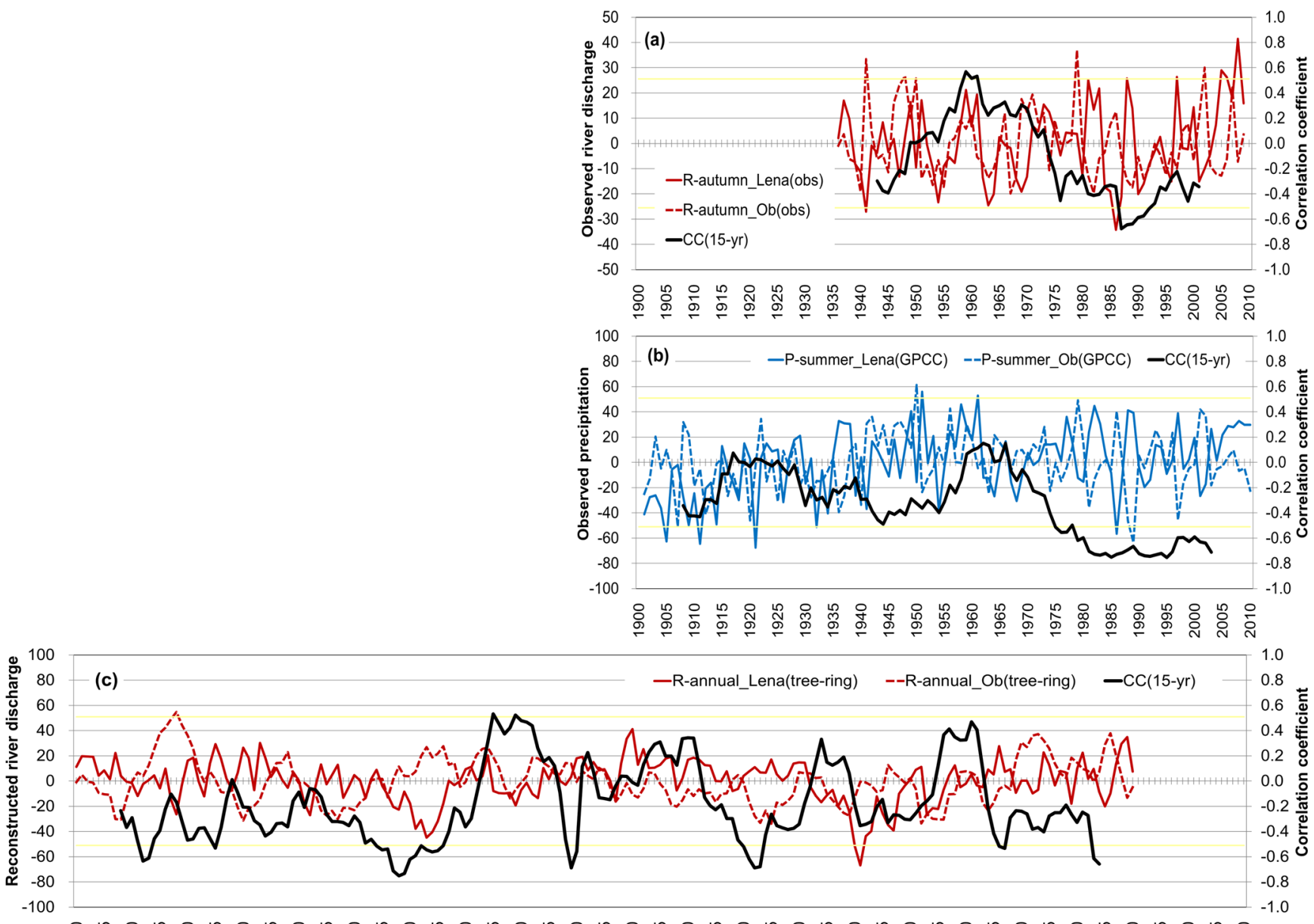

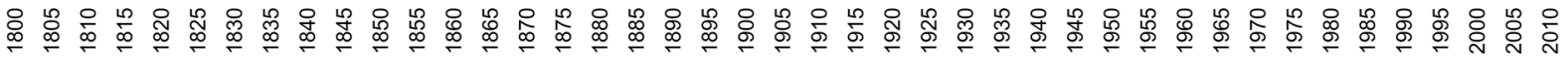

Figure 2. Time series of (a) observed autumn $R$ during 1936-2009, (b) observed summer $P$ during 1901-2010, and (c) tree-ringreconstructed annual $R$ during 1800-1990 of the Lena and Ob rivers. Red (blue) solid and dashed lines denote the $R(P)$ values of the Lena and $\mathrm{Ob}$, respectively. Thick black lines denote 15-year running correlations between the Lena and Ob $R$ and $P$ values. The confidence levels at 90,95 , and $98 \%$ for the 15 -year correlation are $0.44,0.51$ (yellow lines), and 0.59 . Note that the axes of the $R$ and $P$ are shown on the left side of the panel and the axes of the correlations are shown on the right side.
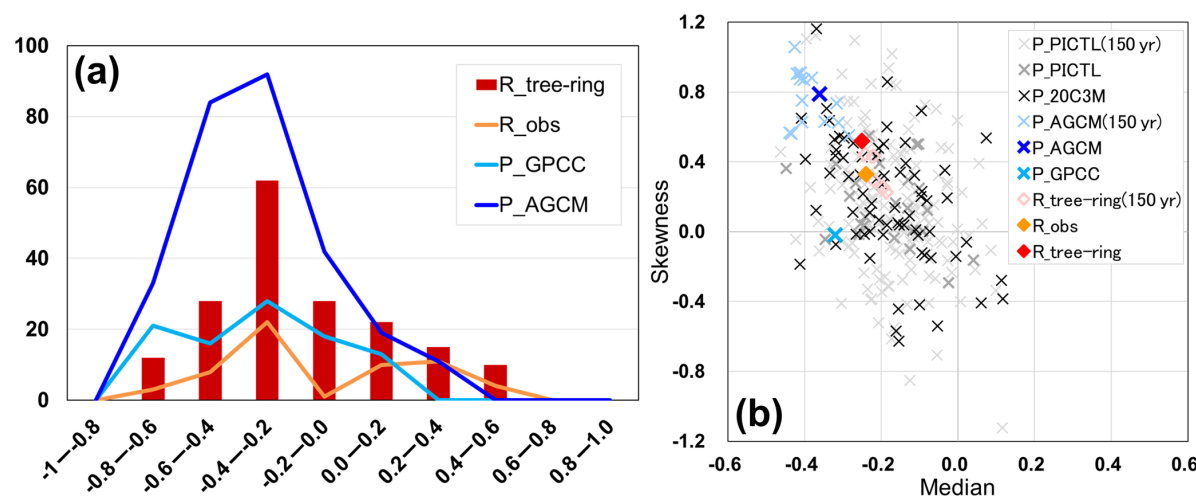

Figure 3. (a) Histogram of 15-year running correlations from the tree-ring-reconstructed annual $R$ (red bars), observed autumn $R$ (orange line), observed summer $P$ (light blue line), and AGCM-simulated summer $P$ (blue line). (b) Scatter diagram between median and skewness of each of the 15-year correlations. Simulated $P$ in the CMIP3 models' simulations (20C3M and PICTL) and subsets of 150-year record for the reconstructed $R$ (five samples), AGCM-simulated $P$ (15 samples), and PICTL-simulated $P$ (over 100 samples) are also plotted. 
Table 2. Median and skewness of the 15 -year running correlations for the tree-ring-reconstructed annual $R$ (Fig. 2c), observed autumn $R$ (Fig. 2a), observed summer $P$ (Fig. 2b), and simulated summer $P$. The observed $P$ and simulated $P$ are based on the GPCC and AGCM. A histogram and scatter diagram for these values are shown in Fig. $3 \mathrm{a}$ and b. Values in brackets indicate the range of statistics calculated from five (15) subsets of 150-year records for the reconstructed $R$ (simulated $P$ ). The results with bold values are robust based on the long-term records.

\begin{tabular}{lrr}
\hline & Median & Skewness \\
\hline R_tree-ring & $\mathbf{- 0 . 2 5}$ & $\mathbf{0 . 5 2}$ \\
& $(-0.24$ to -0.19$)$ & $(0.23$ to 0.44$)$ \\
$R$ _obs. & -0.24 & 0.33 \\
$P \_$GPCC & -0.32 & -0.02 \\
$\boldsymbol{P}$ _AGCM & $\mathbf{- 0 . 3 6}$ & $\mathbf{0 . 7 9}$ \\
& $(-0.44$ to -0.28$)$ & $(0.55$ to 1.06$)$ \\
\hline
\end{tabular}

tive) value. As a result, the medians of the 15-year running correlations in the observation and reconstruction were negative and their skewnesses were positive, although the skewness of observed $P$ was nearly zero (Fig. 3 b and Table 2). Therefore, the interannual variation in $R$ values of the Lena and $\mathrm{Ob}$ rivers and the interannual variation in $P$ values of the Lena and $\mathrm{Ob}$ rivers has tended to be out of phase during the past 2 centuries. This may suggest that the east-west seesaw pattern frequently emerges over Siberia.

\subsubsection{Simulated precipitation}

To determine the intrinsic atmospheric circulation associated with the variation in summer $P$, we analyzed the AGCM control simulation. As with the reconstructed $R$, the correlations of simulated summer $P$ between the Lena and $\mathrm{Ob}$ regions were largely negative. The histogram of the correlations of simulated $P$ was distributed in the negative side (blue line in Fig. 3a), the median was negative, and the skewness was positive (blue cross marks in Fig. 3 b and Table 2). Compared to the reconstructed $R$, the distribution of simulated $P$ was more negative than positive (Fig. 3a) and the median and skewness from the simulated summer $P$ (Table 2) tended to be more negative and positive, respectively (Fig. 3b). The results indicate that atmospheric internal variability in summer leads to the negative correlation of summer $P$. The AGCM control simulation has no external forcing, and boundary conditions such as SST, sea ice, solar activity, and GHG are fixed. Consequently, the variation in simulated $P$ and $Z 500$ in the control simulation can be interpreted as internal variability in the model.

The 20C3M and PICTL simulations in the CMIP3 coupled models provided more evidence for intrinsic atmospheric variability, including air-sea interactions. The medians and skewness of the correlations of summer $P$ between the Lena and $\mathrm{Ob}$ regions in the CMIP3 simulations were plotted in
Fig. 3b (black and gray cross marks); the plotted marks were largely distributed in the upper-left side and the median and skewness also tended to be negative and positive, respectively, while they were well scattered. This suggests that some models failed to reproduce the summer $P$ variability and atmospheric circulation over Siberia. However, note that many simulation results were plotted around the tree-ringreconstructed $R$ and most results from the CMIP3 simulations were distributed toward the center compared to those from the AGCM control simulation (Fig. 3b). These results imply some effects of air-sea interactions on the $P$ variability over the Lena and $\mathrm{Ob}$. This is discussed in the final section.

As a result, similar to the observation and reconstruction, the AGCM and CMIP3 simulations demonstrated that the $P$ over the Lena and $\mathrm{Ob}$ tends to be out of phase. While there were weak and positive correlations of summer $P$ in several periods (Figs. 2 and 3a), we focused on the negative correlation and further examined summertime atmospheric circulation pattern associated with the $P$ over Siberia.

\subsection{Atmospheric circulation associated with the negative correlation of precipitation}

To identify summertime dominant atmospheric circulation patterns associated with summer $P$ variability, we performed an empirical orthogonal function (EOF) analysis on summer $Z 500$ over the three great Siberian river basins (blue inset box in Fig. 4). The spatial pattern of the first EOF mode (EOF1) is the cyclonic circulation anomaly centered in the vicinity of the coast in central Siberia (not shown). This pattern only enhances the eastward moisture transport over Siberia, and the effect on moisture convergence-divergence over the Lena and $\mathrm{Ob}$ regions is small. The EOF2 indicated an east-west seesaw pattern similar to Fukutomi et al. (2003). While Fig. 4 is the spatial pattern of EOF2 based on the JRA-55, the result of 20CR showed a similar pattern, for which the pattern correlation was 0.89 . This seesaw pattern of EOF2 directly affects moisture convergence and divergence over the two river basins and results in changes in the $P$ over the regions.

To confirm the effects of the east-west seesaw pattern on the $P$, we compared the difference in $Z 500$ over the western and eastern Siberian regions (west-east difference in $Z 500$ : $\left.\triangle Z 500_{\mathrm{WE}}\right)$ and the difference in $P$ over the Lena and $\mathrm{Ob}$ regions (Lena-Ob difference in $P: \Delta P_{\mathrm{LO}}$ ). We defined the Lena and $\mathrm{Ob}$ regions for $P$ (green inset boxes in Fig. 4), which cover almost all of the basins, while the regions for the $Z 500$ were shifted $10^{\circ}$ westward (purple inset boxes), which covered almost all of the negative and positive centers of action of EOF2. As described in the introduction, when Z500 anomalies are negative over the east and positive over the west as shown in Fig. 4, $P$ anomalies must be positive over the Lena region and negative over the $\mathrm{Ob}$ region. As expected, $\Delta P_{\text {LO }}$ was positively correlated with $\Delta Z 500_{\mathrm{WE}}$. The correlation coefficients were 0.72 for the JRA-55 and 0.60 for 


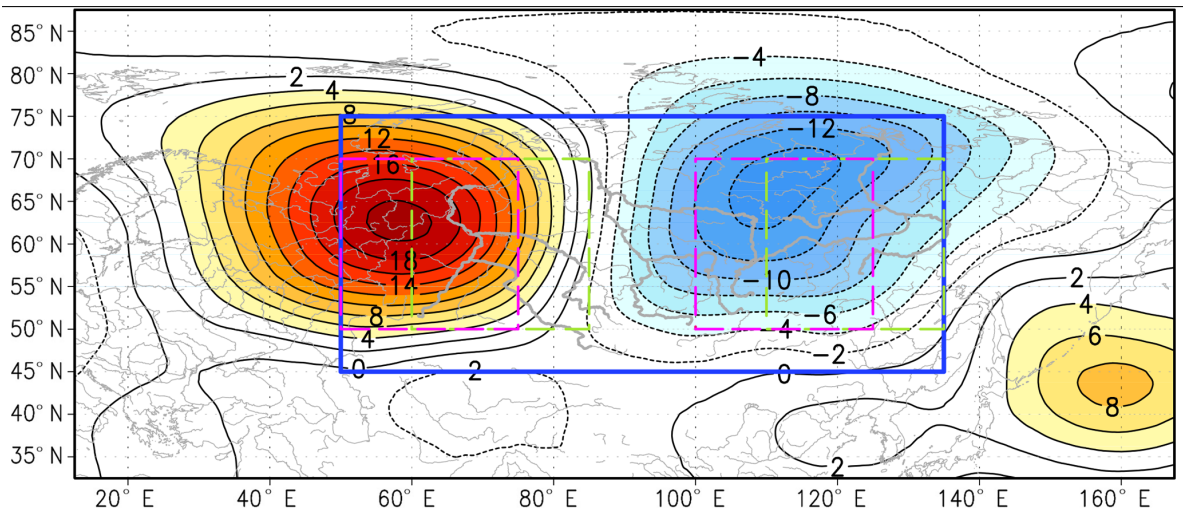

Figure 4. Spatial pattern of EOF2 (19.9\% of explained variance) for the summertime $Z 500$ over Siberia (blue line inset box: $45-75^{\circ} \mathrm{N}$, $50-135^{\circ} \mathrm{E}$, covering the three great Siberian rivers). Green (magenta) dashed inset boxes cover almost all areas of the Lena and Ob river basins (western and eastern centers of action of EOF2). The EOF analysis is based on JRA-55.

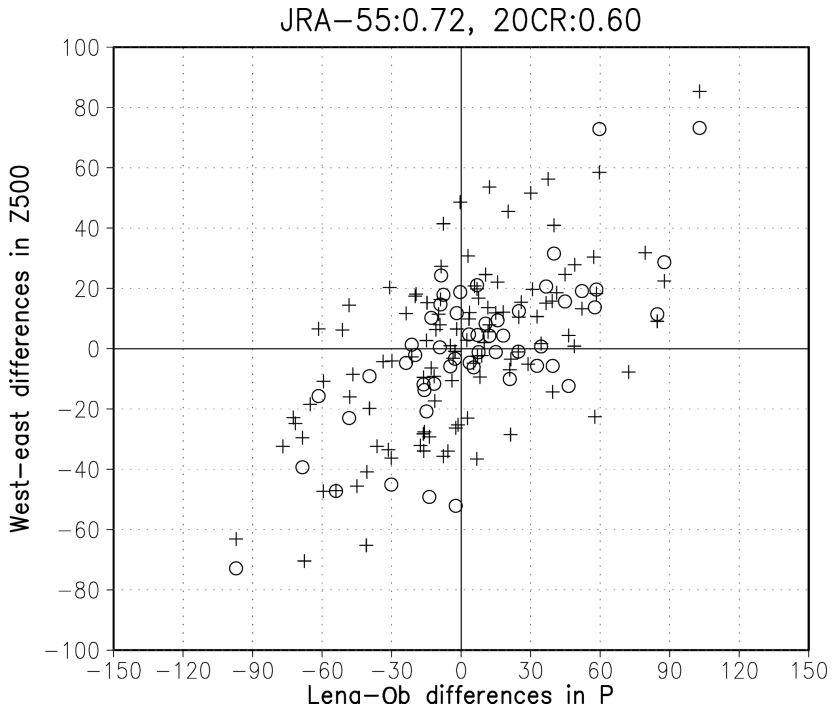

Figure 5. Scatter plot of the summer $P$ differences between the Lena and $\mathrm{Ob}$ regions $\left(\Delta P_{\mathrm{LO}}\right)$ and the summer $Z 500$ differences between the western and eastern Siberian regions $(\triangle Z 500 \mathrm{WE})$. The areas of $\Delta P_{\mathrm{LO}}(\triangle Z 500 \mathrm{WE})$ are defined as the green (purple) dashed inset boxes in Fig. 4. The $\triangle Z 500 \mathrm{WE}$ values based on JRA-55 and $20 \mathrm{CR}$ are plotted as marked with circles and crosses. Correlation coefficients between $\Delta P_{\mathrm{LO}}$ and $\Delta Z 500_{\mathrm{WE}}$ are shown in the upper side of the scatter plot.

the 20CR, both significant above the $99 \%$ confidence level (Fig. 5).

Similar results (i.e., the east-west seesaw pattern of EOF2 and the positive correlation between the $\Delta P_{\mathrm{LO}}$ and $\triangle Z 500_{\mathrm{WE}}$ ) were obtained in the AGCM control simulation and in the 20C3M and PICTL simulations from the CMIP3 coupled models, while some CMIP3 simulations failed to reproduce these features. The pattern correlation of the EOF2 patterns between the JRA-55 and AGCM was 0.83 . The pattern correlations with JRA-55 for the 20C3M and PICTL simulations ranged from -0.62 to 0.94 , but those in $81 \%$ of the $20 \mathrm{C} 3 \mathrm{M}$ and $76 \%$ of the PICTL simulations were greater than 0.7. Several CMIP3 models simulated the seesaw pattern in the EOF3. These results from the AGCM and CMIP3 simulations indicated that the seesaw pattern emerges as a dominant mode of the summertime atmospheric circulation over Siberia. The correlation between the $\Delta P_{\mathrm{LO}}$ and $\triangle Z 500_{\mathrm{WE}}$ in the AGCM was 0.55 for the entire period of the 295-year record and 0.53-0.63 for the 15 subsets of 150-year records. The correlations between the $\Delta P_{\mathrm{LO}}$ and $\Delta Z 500_{\mathrm{WE}}$ in $94 \%$ of the $20 \mathrm{C} 3 \mathrm{M}$ and $90 \%$ of the PICTL simulations were greater than 0.7 . The above results in the simulations also indicated that the east-west seesaw pattern is related with the negative correlation of $P$.

Therefore, the results of the simulations with the AGCM and CMIP3 models were basically consistent with the reconstructed $R$ and observations, and they support the linkage between the summertime east-west seesaw pattern over Siberia and the out-of-phase $P$ over the Lena and $\mathrm{Ob}$ regions.

\section{Summary and discussion}

We examined the long-term variations in the $R$ values and corresponding $P$ values for the Lena in eastern Siberia and the $\mathrm{Ob}$ in western Siberia based on observations, tree-ring reconstructions, and simulations with the AGCM and CMIP3 models. The observations during the past 7 decades indicated that correlations of observed $R$ values between the Lena and Ob were negative during the 1980s to mid-1990s as in Fukutomi et al. (2003), but positive during the mid-1950s to 1960 s and became weak in recent decades (Fig. 2a). This suggests that the relationship between the Lena and $\mathrm{Ob} R$ values was different in each of the epochs. However, the reconstructed $R$ values during the past 2 centuries indicated that the Lena and $\mathrm{Ob}$ tended to be negatively correlated, i.e., out of phase (Figs. 2c and 3). The observed $P$ values over eastern and western Siberia also frequently had negative correlations in 
the 20th century (Fig. 2b), which were affected by the eastwest seesaw pattern of summertime atmospheric circulation over Siberia (Fig. 4). Compared to the reconstructed $R$ and observed $P$, the simulated $P$ in the AGCM control simulation indicated more frequent negative correlations in association with the seesaw pattern (Fig. 3). Because of the fixed boundary conditions, the control simulation demonstrated that the negative correlation and the seesaw pattern emerge as summertime atmospheric internal variability over Siberia. Although the results from the 20C3M and PICTL simulations vary among the models, they basically support the features above. As a consequence, the east-west seesaw pattern of large-scale circulation frequently emerges as summertime atmospheric internal variability over Siberia and induces the convergence-divergence of moisture flux and associated opposite anomaly, i.e., negative correlation, of the summer $P$ values over eastern and western Siberia, resulting in the outof-phase autumn $R$ values of the Lena and Ob rivers. Therefore, the summertime atmospheric internal variability in the seesaw pattern over Siberia is a key factor influencing the water cycles in this region.

The results from the AGCM and CMIP3 simulations and previous studies give us further implication for the $P$ variability and associated atmospheric circulation pattern over Siberia. Compared to the AGCM control simulation, the CMIP3 simulations mostly plotted around the reconstructed $R$ (Fig. 3b), suggesting that the air-sea interaction acts as a damping of the seesaw pattern and breaks the negative correlation of $P$. An external forcing such as a SST or sea ice anomaly may affect large-scale circulation and $P$ over Siberia. Moreover, while the negative correlation dominated in the $P$ variations between eastern and western Siberia, the positive and weak correlation periods were also seen in some periods as shown by the time series in Fig. 2. This implies that, in addition to the east-west seesaw pattern of atmospheric internal variability, there are other effects on the summertime $P$ variability over Siberia. Indeed, Sun et al. (2015) reported the remote influence of Atlantic multidecadal variation, which is an oscillation of North Atlantic SST between basin-wide uniform warm and cold conditions, on the variation in summertime $P$ over Siberia on decadal or multidecadal timescales. Iwao and Takahashi $(2006,2008)$ indicated that the effects of quasi-stationary Rossby waves originated from blocking anticyclones in the North AtlanticEuropean sector on the precipitation seesaw pattern between northeast Asia and eastern Siberia. Ding and Wang (2005) showed a circumglobal teleconnection with zonal wave number 5 structure in the Northern Hemisphere midlatitude, resulting in $P$ anomalies in various areas of the world including Siberia. Iijima et al. (2016) indicated the impact of enhanced storm activity on the increase in $P$ and permafrost degradation in eastern Siberia during the mid-2000s and they discussed the relationship with the Arctic dipole anomaly associated with the sea ice reduction. As in Iijima et al. (2016), Fujinami et al. (2016) and Hiyama et al. (2016) also showed similar results for the $P$ over eastern Siberia. While they studied somewhat different timescales and different regions, the $P$ variability over the Lena and $\mathrm{Ob}$ must be affected by a combination of these processes including internal variability. However, this study did not examine those specific effects and future work is needed. In addition, it seems that the differences between the 20C3M and PICTL simulations are not large (Fig. 3b), and there should be no significant influence of changes in GHGs on the $P$ variability in Siberia, while $P$ in future projections will increase under global warming (IPCC, 2007, 2013).

Data availability. The observed and tree-ring-reconstructed discharge data are available at the ArcticRIMS (2018) and MacDonald et al. (2007) websites, as described in the text. The GPCC precipitation and the 20CR reanalysis are available at the NOAA ESRL website (GPCC: https://www.esrl.noaa.gov/psd/data/ gridded/data.gpcc.html, 20CR: https://www.esrl.noaa.gov/psd/data/ 20thC_Rean/; NOAA ESRL, 2018a, b). The JRA-55 is available at the JRA project website (http://jra.kishou.go.jp/JRA-55/index_ en.html) (JRA, 2018). The AGCM control simulation is our original data and please contact the first author (Kazuhiro Oshima, oshima@ies.or.jp), if needed. The CMIP3 simulations are available at the PCMDI website (https://pcmdi.llnl.gov/mips/cmip3/) (PCMDI, 2018).

Competing interests. The authors declare that they have no conflict of interest.

Acknowledgements. This work was supported partly by JSPS KAKENHI grant numbers 24241009, 26340018, and 17H01870, the GRENE Arctic Climate Change Research Project, the Arctic Challenge for Sustainability (ArCS) Project, and the Joint Research Program of the Japan Arctic Research Network Center.

Edited by: Michel Crucifix

Reviewed by: Klaus Arpe, Stefan Hagemann and Xiangdong Zhang

\section{References}

Aagaard, K. and Carmack, E. C.: The role of sea ice and other fresh water in the Arctic circulation, J. Geophys. Res.-Oceans, 94, 14485-14498, https://doi.org/10.1029/JC094iC10p14485, 1989.

Aagaard, K. and Carmack, E. C.: The Arctic Ocean and Climate: A Perspective, in: The Polar Oceans and Their Role in Shaping the Global Environment, edited by: Johannessen, O. M., Muench, R. D., and Overland, J. E., American Geophysical Union, Washington, D.C., USA, 5-20, https://doi.org/10.1029/GM085p0005, 1994.

ArcticRIMS: Observed river discharge, available at: http://rims.unh. edu/; last access: 26 April 2018.

Arpe, K., Leroy, S. A. G., Wetterhall, F., Khan, V., Hagemann, S., and Lahijani, H.: Prediction of the Caspian Sea Level using ECMWF seasonal forecasts and reanalysis, Theor. Appl. Cli- 
matol., 117, 41-60, https://doi.org/10.1007/s00704-013-0937-6, 2013.

Berezovskaya, S.: Compatibility analysis of precipitation and runoff trends over the large Siberian watersheds, Geophys. Res. Lett., 31, L21502, https://doi.org/10.1029/2004g1021277, 2004.

Chen, M., Xie, P., Janowiak, J. E., and Arkin, P. A.: Global land precipitation: A 50-yr monthly analysis based on gauge observations, J. Hydrometeorol., $\quad 3, \quad 249-266, \quad$ https://doi.org/10.1175/15257541(2002)003<0249:GLPAYM>2.0.CO;2, 2002.

Compo, G. P., Whitaker, J. S., Sardeshmukh, P. D., Matsui, N., Allan, R. J., Yin, X., Gleason, B. E., Vose, R. S., Rutledge, G., Bessemoulin, P., Brönnimann, S., Brunet, M., Crouthamel, R. I., Grant, A. N., Groisman, P. Y., Jones, P. D., Kruk, M. C., Kruger, A. C., Marshall, G. J., Maugeri, M., Mok, H. Y., Nordli, Ø., Ross, T. F., Trigo, R. M., Wang, X. L., Woodruff, S. D., and Worley, S. J.: The Twentieth Century Reanalysis Project, Q. J. Roy. Meteor. Soc., 137, 1-28, https://doi.org/10.1002/qj.776, 2011.

Ding, Q. and Wang, B.: Circumglobal Teleconnection in the Northern Hemisphere Summer, J. Climate, 18, 3483-3505, https://doi.org/10.1175/JCLI3473.1, 2005.

Fedorov, A. N., Gavriliev, P. P., Konstantinov, P. Y., Hiyama, T., Iijima, Y., and Iwahana, G.: Estimating the water balance of a thermokarst lake in the middle of the Lena River basin, eastern Siberia, Ecohydrology, 7, 188-196, https://doi.org/10.1002/eco.1378, 2014.

Fujinami, H., Yasunari, T., and Watanabe, T.: Trend and inter-annual variation in summer precipitation in eastern Siberia in re-cent decades, Int. J. Climatol., 36, 355-368, https://doi.org/10.1002/joc.4352, 2016.

Fujiwara, J.: Climate change and migration policy in the Republic of Sakha, in FY2010 FR22 Research Project Report "Global warming and the Human-Nature Dimension in Siberia: Social adaptation to the changes of the terrestrial ecosystem, with an emphasis on water environments (RIHN Project C-07), edited by: Hiyama, T., Research Institute for Humanity and Nature, Hiyama, 192-196, 2011. (in Japanese).

Fukutomi, Y., Igarashi, H., Masuda, K., and Yasunari, T.: Interannual Variability of Summer Water Balance Components in Three Major River Basins of Northern Eurasia, J. Hydrometeorol., 4, 283-296, https://doi.org/10.1175/15257541(2003)4<283:IVOSWB>2.0.CO;2, 2003.

Fukutomi, Y., Masuda, K., and Yasunari, T.: Role of storm track activity in the interannual seesaw of summer precipitation over northern Eurasia, J. Geophys. Res.-Atmos., 109, D02109, https://doi.org/10.1029/2003JD003912, 2004.

Fukutomi, Y., Masuda, K., and Yasunari, T.: Cyclone activity associated with the interannual seesaw oscillation of summer precipitation over northern Eurasia, Global Planet. Change, 56, 387398, https://doi.org/10.1016/j.gloplacha.2006.07.026, 2007.

Fukutomi, Y., Masuda, K., and Yasunari, T.: Spatiotemporal structures of the intraseasonal oscillations of precipitation over northern Eurasia during summer, Int. J. Climatol., 32, 710-726, https://doi.org/10.1002/joc.2293, 2012.

Harada, Y., Kamahori, H., Kobayashi, C., Endo, H., Kobayashi, S., Ota, Y., Onoda, H., Onogi, K., Miyaoka, K., and Takahashi, K.: The JRA-55 Reanalysis: Representation of Atmospheric Circula- tion and Climate Variability, J. Meteorol. Soc. Jpn., 94, 269-302, https://doi.org/10.2151/jmsj.2016-015, 2016.

Hiyama, T., Fujinami, H., Kanamori, H., Ishige, T., and Oshima, K.: Interdecadal modulation of the interannual variability in precipitation and atmospheric circulation pattern over northern Eurasia, Environ. Res. Lett., 11, 065001, https://doi.org/10.1088/17489326/11/6/065001, 2016.

Iijima, Y., Fedorov, A. N., Park, H., Suzuki, K., Yabuki, H., Maximov, T. C., and Ohata, T.: Abrupt increases in soil temperatures following increased precipitation in a permafrost region, central Lena River basin, Russia, Permafrost Periglac., 21, 30-41, https://doi.org/10.1002/ppp.662, 2010.

Iijima, Y., Ohta, T., Kotani, A., Fedorov, A. N., Kodama, Y., and Maximov, T. C.: Sap flow changes in relation to permafrost degradation under increasing precipitation in an eastern Siberian larch forest, Ecohydrology, 7, 177-187, https://doi.org/10.1002/eco.1366, 2014.

Iijima, Y., Nakamura, T., Park, H., Tachibana, Y., and Fedorov, A. N.: Enhancement of Arctic storm activity in relation to permafrost degradation in eastern Siberia, Int. J. Climatol., 36, 4265-4275, https://doi.org/10.1002/joc.4629, 2016.

IPCC, Climate Change 2007: The Physical Science Basis. Contribution of Working Group I to the Fourth Assessment Report (AR4) of the Intergovernmental Panel on Climate Change, edited by: Solomon, S., Qin, D., Manning, M., Chen, Z., Marquis, M., Averyt, K. B., Tignor, M., and Miller, H. L., Cambridge University Press, New York, USA, 996 pp., 2007.

IPCC, Climate Change 2013: The Physical Science Basis. Contribution of Working Group I to the Fifth Assessment Report (AR5) of the Intergovernmental Panel on Climate Change, edited by: Stocker, T. F., Qin, D., Plattner, G.-K., Tignor, M., Allen, S. K., Boschung, J., Nauels, A., Xia, Y., Bex, V., and Midgley, P. M., Cambridge University Press, New York, USA, 1535 pp., 2013.

Iwao, K. and Takahashi, M.: Interannual change in summertime precipitation over northeast Asia, Geophys. Res. Lett., 33, L16703, https://doi.org/10.1029/2006GL027119, 2006.

Iwao, K. and Takahashi, M.: A Precipitation Seesaw Mode between Northeast Asia and Siberia in Summer Caused by Rossby Waves over the Eurasian Continent, J. Climate, 21, 2401-2419, https://doi.org/10.1175/2007JCLI1949.1, 2008.

Iwasaki, H., Saito, H., Kuwao, K., Maximov, T. C., and Hasegawa, S.: Forest decline caused by high soil water conditions in a permafrost region, Hydrol. Earth Syst. Sci., 14, 301-307, https://doi.org/10.5194/hess-14-301-2010, 2010.

JRA: JRA-55, available at: http://jra.kishou.go.jp/JRA-55/index_ en.html, last access: 26 April 2018.

Kobayashi, S., Ota, Y., Harada, Y., Ebita, A., Moriya, M., Onoda, H., Onogi, K., Kamahori, H., Kobayashi, C., Endo, H., Miyaoka, K., and Takahashi, K.: The JRA-55 Reanalysis: General Specifications and Basic Characteristics, J. Meteorol. Soc. Jpn., 93, 5-48, https://doi.org/10.2151/jmsj.2015-001, 2015.

Kurita, N., Sugimoto, A., Fujii, Y., Fukazawa, T., Makarov, V. N., Watanabe, O., Ichiyanagi, K., Numaguti, A., and Yoshida, N.: Isotopic composition and origin of snow over Siberia, J. Geophys. Res., 110, D13102, https://doi.org/10.1029/2004JD005053, 2005.

MacDonald, G. M., Kremenetski, K. V., Smith, L. C., and Hidalgo, H. G.: Recent Eurasian river discharge to the Arctic Ocean in the context of longer-term dendro- 
hydrological records, J. Geophys. Res., 112, G04S50, https://doi.org/10.1029/2006jg000333, 2007.

McClelland, J. W., Holmes, R. M., Peterson, B. J., and Stieglitz, M.: Increasing river discharge in the Eurasian Arctic: Consideration of dams, permafrost thaw, and fires as potential agents of change, J. Geophys. Res.-Atmos., 109, D18102, https://doi.org/10.1029/2004JD004583, 2004.

McClelland, J. W., Déry, S. J., Peterson, B. J., Holmes, R. M., and Wood, E. F.: A pan-arctic evaluation of changes in river discharge during the latter half of the 20th century, Geophys. Res. Lett., 33, L06715, https://doi.org/10.1029/2006g1025753, 2006.

Meehl, G. A., Covey, C., Taylor, K. E., Delworth, T., Stouffer, R. J., Latif, M., McAvaney, B., and Mitchell, J. F. B.: THE WCRP CMIP3 Multimodel Dataset: A New Era in Climate Change Research, B. Am. Meteorol. Soc., 88, 1383-1394, https://doi.org/10.1175/bams-88-9-1383, 2007.

NOAA ESRL: GPCC precipitation, available at: https://www.esrl. noaa.gov/psd/data/gridded/data.gpcc.html, last access: 26 April 2018a.

NOAA ESRL: 20CR reanalysis, available at: https://www.esrl.noaa. gov/psd/data/20thC_Rean/, last access: 26 April 2018b.

Numaguti, A.: Origin and recycling processes of precipitating water over the Eurasian continent: Experiments using an atmospheric general circulation model, J. Geophys. Res., 104, 1957-1972, https://doi.org/10.1029/1998JD200026, 1999.

Numaguti, A., Takahashi, M., Nagajima, T., and Sumi, A.: Development of an atmospheric general circulation model. In Reports of a New Program for Center Basic Research Studies, Studies of Global Environment Change with Special Reference to Asia and Pacific Regions, Rep. I-3, 1-27, CCSR, Tokyo, 1995.

Numaguti, A., Sugata, S., Takahashi, M., Nakajima, T., and Sumi, A.: Study on the climate system and mass transport by a climate model, CGER's Supercomputer Monograph Report, National Institute for Environmental Studies, vol. 3, 91 pp., 1997.

Ogata, K., Tachibana, Y., Udagawa, Y., Oshima, K., and Yoshida, K.: Influence of sea ice anomaly in the Pacific sector of the Southern Ocean upon atmospheric circulation using an AGCM, Umi to Sora, 89, 19-23, 2013 (in Japanese).

Ohta, T., Maximov, T. C., Dolman, A. J., Nakai, T., van der Molen, M. K., Kononov, A. V., Maximov, A. P., Hiyama, T., Iijima, Y., Moors, E. J., Tanaka, H., Toba, T., and Yabuki, H.: Interannual variation of water balance and summer evapotranspiration in an eastern Siberian larch forest over a 7-year period (1998-2006), Agr. Forest Meteorol., 148, 1941-1953, https://doi.org/10.1016/j.agrformet.2008.04.012, 2008.

Ohta, T., Kotani, A., Iijima, Y., Maximov, T. C., Ito, S., Hanamura, M., Kononov, A. V., and Maximov, A. P.: Effects of waterlogging on water and carbon dioxide fluxes and environmental variables in a Siberian larch forest, 1998-2011, Agr. Forest Meteorol., 188, 64-75, https://doi.org/10.1016/j.agrformet.2013.12.012, 2014.

Oshima, K., Tachibana, Y., and Hiyama, T.: Climate and year-toyear variability of atmospheric and terrestrial water cycles in the three great Siberian rivers, J. Geophys. Res.-Atmos., 120, 30433062, https://doi.org/10.1002/2014JD022489, 2015.
PCMDI: CMIP3 simulations, available at: https://pcmdi.llnl.gov/ mips/cmip3/, last access: 26 April 2018.

Rawlins, M. A., Willmott, C. J., Shiklomanov, A., Linder, E., Frolking, S., Lammers, R. B., and Vörösmarty, C. J.: Evaluation of trends in derived snowfall and rainfall across Eurasia and linkages with discharge to the Arctic Ocean, Geophys. Res. Lett., 33, L07403, https://doi.org/10.1029/2005GL025231, 2006.

Sakai, T., Hatta, S., Okumura, M., Hiyama, T., Yamaguchi, Y., and Inoue, G.: Use of Landsat TM/ETM+ to monitor the spatial and temporal extent of spring breakup floods in the Lena River, Siberia, Int. J. Remote Sens., 36, 719-733, https://doi.org/10.1080/01431161.2014.995271, 2015.

Schneider, U., Becker, A., Finger, P., Meyer-Christoffer, A., Ziese, M., and Rudolf, B.: GPCC's new land surface precipitation climatology based on quality-controlled in situ data and its role in quantifying the global water cycle, Theor. Appl. Climatol., 115, 15-40, https://doi.org/10.1007/s00704-013-0860-x, 2013.

Serreze, M. C., Bromwich, D. H., Clark, M. P., Etringer, A. J., Zhang, T., and Lammers, R.: Large-scale hydro-climatology of the terrestrial Arctic drainage system, J. Geophys. Res., 108, 8160, https://doi.org/10.1029/2001jd000919, 2003.

Shiklomanov, A. I. and Lammers, R. B.: Record Russian river discharge in 2007 and the limits of analysis, Environ. Res. Lett., 4, 045015, https://doi.org/10.1088/1748-9326/4/4/045015, 2009.

Sun, C., Li, J., and Zhao, S.: Remote influence of Atlantic multidecadal variability on Siberian warm season precipitation, Sci. Rep.-UK, 5, 16853, https://doi.org/10.1038/srep16853, 2015.

Tachibana, Y., Oshima, K., and Ogi, M.: Seasonal and interannual variations of Amur River discharge and their relationships to large-scale atmospheric patterns and moisture fluxes, J. Geophys. Res., 113, D16102, https://doi.org/10.1029/2007JD009555, 2008.

Takashima, H., Yatagai, A., Kawamoto, H., Arakawa, O., and Kamiguchi, K.: Hydrological balance over northern Eurasia from gauge-based high-resolution daily precipitation data, in: From Headwaters to the Ocean: Hydrological Change and Watershed Management, edited by: Taniguchi, M., Burnett, W. C., Fukushima, Y., Haigh, M., and Umezawa, Y., Taylor \& Francis Group, London, UK, 37-41, 2009.

Yatagai, A., Kamiguchi, K., Arakawa, O., Hamada, A., Yasutomi, N., and Kitoh, A.: APHRODITE: Constructing a longtermdaily gridded precipitation dataset for Asia based on a dense network of rain gauges, B. Am. Meteorol. Soc., 93, 1401-1415, https://doi.org/10.1175/BAMS-D-11-00122.1, 2012.

Ye, H., Ladochy, S., Yang, D., Zhang, T., Zhang, X., and Ellison, M.: The Impact of Climatic Conditions on Seasonal River Discharges in Siberia, J. Hydrometeorol., 5, 286-295, https://doi.org/10.1175/15257541(2004)005<0286:TIOCCO>2.0.CO;2, 2004.

Zhang, X., He, J., Zhang, J., Polyakov, I., Gerdes, R., Inoue, J., and $\mathrm{Wu}, \mathrm{P}$. : Enhanced poleward moisture transport and amplified northern high-latitude wetting trend, Nat. Clim. Change, 3, 47-51, https://doi.org/10.1038/nclimate1631, 2012. 